[Agr. Biol. Chem., Vol. 30, No. 2, p. 200 201, 1966]

\title{
A New Mint (Variety of Mentha aquatica L.) Containing (-)-Isopinocamphone as a Major Constituent of Essential Oil ${ }^{*}$
}

Sir:

Essential oils from various mint species generally contain predominantly monocyclic terpenes. Several investigators ${ }^{1 \sim 3)}$ reported the presence of carvone or pulegone in the essential oils of Mentha aquatica in South Europe. Reitsema" found a menthofuran-dominant aquatica in America, and this furan was also detected in European aquatica oil by Hegnaur. ${ }^{\text {') }}$ In the present paper we wish to report on a new chemical strain of aquatica, containing (-)-isopinocamphone, a bicyclic monoterpene ketone, as a major constituent. The material seeds of $M$. aquatica were imported from the following countries; Belgium, Plantentuin der Rijksuniversiteit to Gent; Belgium, Institut et Jardin de Botanique de l'Université de Liége; France, Jardin Botanique Ville de Nantes; Italy, Instituto ed Orto Botanico dell' Univ. di Rome; Portugal, Hortus Botanicus Coimbra. They were cultivated in Okayama University and Kurashiki Experimental Station for Agriculture.

By analyzing the essential oils obtained from the above mentioned aquatica herbs by gas chromatography (column, SAIB 20\% on Gelite 545; column temp., $155^{\circ} \mathrm{C}$; carrier gas, hydrogen; flow rate, $65 \mathrm{ml} / \mathrm{min}$.), we divided aquatica mint into following three chemical strains.

Linalool strain seems to be very similiar

1) Ber. Schimmel, 1389 , October 55; 1913, April 70; 1932, 45.

2) T. Sacco, Riechstoffe und Aromen, 9, 287 (1959).

3) G. Romeo and U. Giuffre, Annali. Chim. Applic., 17, 83 (1927).

4) H. Reitsema, J. Am. Pharm. Assoc. Sci. Ed., 43, 414 (1954).

5) R. Hegnauer, "Die ätherischen Ole" Ed. VII by Gildemeister (Akademie Verlag, Berlin, 1961), p. 393.

* This report was presented at the 9th Symposium of Chemistry of Perfume, Terpene and Essential oil in Japan, on 17th, Oct., 1965 at Kumamoto University. to Mentha citrata $^{61}$ from chemical and morphological point of view. Menthofuran in the second oil was identified by infrared spectrum, thin-layer chromatography (a purple red spot by vanillin sulfuric acid reagent) and Flückiger reagent test. It will be surely identical with American aquatica reported by Reitsema. ${ }^{4}$

The essential oil obtained from third strain showed strong absorption at $1700 \mathrm{~cm}^{-1}$ and gave semicarbazone of m.p. $232^{\circ} \mathrm{C}$ in the yield of $30 \%$. The oil regenerated from this semicarbazone by treatment with acid media showed two peaks in the gas chromatogram, the later of which was determined to coincide with the main peak of aquatica original oil; retention time relative to $(-)$-menthol was 0.88 . This indicates that aquatica ketone is sensitive to acid and isomerizes to a stable isomer. The original ketone was isolated purely by silica column chromatography (first eluting solvent, petroleum ether, then followed by ether): b.p. $81^{\circ} \mathrm{C} / 5 \mathrm{~mm} .,[\alpha]_{D}^{15}-7.3^{\circ}$ By the reduction with lithium aluminum hydride, a borneol-like smelling crystal (m.p. $40 \sim 45^{\circ} \mathrm{C}$ ) was obtained. From the elementary analysis of its 3,5-dinitrobenzoate (Found: C, 58.70; H, 5.83; Calcd. for $\mathrm{C}_{17} \mathrm{H}_{20} \mathrm{~N}_{2} \mathrm{O}_{6}=$ dinitrobenzoate of $\mathrm{C}_{10} \mathrm{H}_{18} \mathrm{O}: \mathrm{C}, 58.61 ; \mathrm{H}, 5.79 \%$ ), the molecular formula for original ketone was established to be $\mathrm{C}_{10} \mathrm{H}_{16} \mathrm{O}$.

It showed no double bond in the infrared spectrum and gave pinonic acid by potassium permanganate oxidation (identified as semicarbazone of m.p. $204^{\circ} \mathrm{C}$ ). From these results aquatica ketone seemed to be a bicyclic ketone such as pinocamphone or isopinocamphone.

\footnotetext{
6) "The Essential Oil" by E. Guenther (D. Van Nostrand Co., New York, 1949) Vol. III, p. 685; According to Index Kewensis. Mentha citrata Ehrh, is identical with M. aquatica.
} L. 


\begin{tabular}{|c|c|c|c|c|c|}
\hline chemical strain & $n_{\mathrm{D}}^{15}$ & $d_{4}^{15}$ & {$[\alpha]_{D}^{15}$} & $\begin{array}{c}\text { content of major } \\
\text { costituent }\end{array}$ & $\begin{array}{l}\text { origins of } \\
\text { mints }\end{array}$ \\
\hline 1) Linalool strain & 1.4655 & 0.8864 & -9.50 & $\begin{array}{l}43 \% \text { (including } \\
\text { acetate } 22.1 \text { ) }\end{array}$ & France \\
\hline 2) Menthofuran strain & 1.4760 & 0.9115 & +31.02 & $49 \%$ & Belgium \\
\hline 3) Isopinocamphone strain & 1.4750 & 0.8794 & -24.70 & $49 \%$ & $\begin{array}{l}\text { Italy, Belgium } \\
\text { Portugal }\end{array}$ \\
\hline
\end{tabular}

NMR spectrum of this ketone in deuteriochloroform showed the presence of gem-dimethyl (singlets, $9.128 .68^{\tau}$ ) and one methyl (doublet, $8.85,8.73^{\tau}, J=7$ c.p.s.), which support isopinocamphone skeleton. ${ }^{71}$

Then, (-)-isopinocamphone was prepared by hydroboration of (-)-pinene, $[\alpha]_{\mathrm{D}}^{15}-35^{\circ}$ according to Brown's method; ${ }^{8 /}$ b.p. $91 \sim 105^{\circ} \mathrm{C} /$ $20 \mathrm{~mm}$., after silica chromatography, $[\alpha]_{\mathrm{D}}^{15}$ $-8.8^{\circ}$. Infrared spectrum absorption and retention time of $(-)$-isopinocamphone were found to be completely identical with those of aquatica ketone.

This is the first paper which shows the presence of $(-)$-isopinocamphone in the essential oil of the Genus Mentha, while (-)pinocamphone was found in the oil of Hyssopus officinalis L." and ground ivy (Glechoma hederacea L. subsp. grandis (A. Gray) Hara). ${ }^{101}$

7) R. L. Erskine and S. A. Knight, Chem. \& Ind. 1960, Sept. 1160.

8) H.C. Brown and G. Zweifel, J. Am. Chem. Soc., 83, $2550.2951(1961)$.

9) "The Essential Oil" by E. Guenther; Vol. II, p. 442 (1949).

10) Hikino, Kusano and Takemoto; Proceeding of 6 th Symposium of Chem. Perfumery, Terpenes and Essential oils, 115 (1962).
The authors are indebted to Drs. A. Komatsu and T. Yoshida, Takasago Perfumery Co., Ltd., Tokyo for their kind suggestions. They also wish to express their sincere thanks to $\mathrm{Mr}$. T. Nakayama, Okayama Experimental Station for Agriculture for the generous gift of aquatica oil. Thanks are also due to the authorities who sent us the seeds materials of European origins.

This work was supported in a part by a grant-in-aid from Minister of Eduction.

\section{Sumio SHImizu \\ Denei Karasawa \\ Nagamori IKEDA*}

Laboratory of Agricultural Chemistry,

Shinshu University,

Ina, Nagano.

* Laboratory of Plant Breeding, Okayama University,

Tsushima, Okayama. 